\title{
Sala de aula invertida na prática: implementação e avaliação no ensino de matemática
}

\author{
Hugo Luiz Gonzaga Honório ${ }^{1}$, Liamara Scortegagna² \\ ${ }^{1}$ Programa de Mestrado em Educação Matemática (PPGEM) - Universidade Federal de \\ Juiz de Fora (UFJF) - 36036-900 - Juiz de Fora - MG- Brasil \\ ${ }^{2}$ Departamento de Ciência da Computação (DCC) - Universidade Federal de Juiz de \\ Fora (UFJF) - 36036-900 - Juiz de Fora - MG- Brasil \\ hugo.honorio12@gmail.com, liamara@ice.ufjf.br
}

\begin{abstract}
This paper presents an experience report about the implementation of a "Process" for the use of the Flipped Classroom methodology, providing support for collaborative learning in Mathematics Teaching. The process was elaborated and evaluated from a research developed in the Professional Masters in Mathematics Education, implemented in a class of the 9th year of Elementary Education, and the methodology of case study was used to investigate and analyze the behavior and the reactions from the students. With the completion of the Process, it was possible to verify that the students collaborated in the moments of online and face-to-face interactions, from the appropriation of the collaboration elements of the Model 3C. Regarding the Flipped Classroom methodology, the students reported positively this experience, since the availability of reviewing videotapes at any time, as well as the fact that they have a more individualized monitoring by the teacher in the face-to-face moments, has potentiated the teaching and learning process.
\end{abstract}

Resumo. Este trabalho apresenta um relato de experiência sobre a implementação de um "Processo" para a utilização da Metodologia Sala de Aula Invertida, propiciando suporte à aprendizagem colaborativa no Ensino de Matemática. O Processo foi elaborado e avaliado a partir de uma pesquisa desenvolvida no Mestrado Profissional em Educação Matemática, implementado em uma turma do $9^{\circ}$ ano do Ensino Fundamental e, utilizou-se a metodologia de estudo de caso para investigar e analisar o comportamento $e$ as reações dos alunos. Com a efetivação do Processo, pode-se constatar que os alunos colaboraram nos momentos de interações online e presenciais, a partir da apropriação dos elementos de colaboração do Modelo $3 C$ e, quanto a metodologia Sala de Aula invertida, os alunos relataram de forma positiva a experiência, pois a disponibilidade de rever às videoaulas em qualquer momento, bem como o fato destes terem um acompanhamento mais individualizado pelo professor nos momentos presenciais, potencializou o processo de ensino e aprendizagem. 
VI Congresso Brasileiro de Informática na Educação (CBIE 2017)

Anais do XXIII Workshop de Informática na Escola (WIE 2017)

\section{Introdução}

O desenvolvimento da tecnologia de rede mudou a forma como os alunos interagem uns com os outros e com os professores, trazendo a eles a possibilidade de comunicação com outros alunos localizados geograficamente distantes [Jeong; Hmelo-Silver, 2016].

No que diz respeito às aulas de matemática, essas tecnologias possibilitaram uma mudança no modelo pedagógico estático e restrito adotado por muitos docentes. Os ambientes computacionais condicionam as ações quando se tem que resolver uma atividade ou um problema matemático, de modo que as possibilidades experimentais dessas mídias podem ser exploradas, em que se possibilite chegar à elaboração de conjecturas, bem como a sua verificação, por exemplo, inferir propriedades, chegar a generalizações e verificar teoremas [Borba, 2010].

Assim, uma das principais preocupações dos pesquisadores da área é pensar e criar formas de integrar as Tecnologias da Informação e Comunicação (TIC) à prática pedagógica de professores que, no atual cenário educacional, sentem a necessidade de transformar e atualizar e sua atuação em sala de aula. São muitas as metodologias que dinamizam o processo de ensino e aprendizagem a partir da integração das TIC, entre elas temos a Flipped Classroom, conhecida no Brasil como "Sala de Aula Invertida", denominação que foi utilizada nesta pesquisa.

Segundo Kopp, Ebbler e Restad [2013, apud Munhoz, 2015], a característica dessa metodologia é "inverter" o ciclo típico de aquisição de conteúdos e aplicações, de tal forma que os alunos tenham contato antecipado com o conhecimento necessário antes da aula presencial, em algum ambiente virtual de aprendizagem e, no encontro presencial, alunos e professores interagem de forma ativa para esclarecer, trabalhar e aplicar o conhecimento que foi construído no ambiente online.

Este relato tem como objetivo apresentar a implementação de um "Processo" voltado para o ensino de um tópico da disciplina de matemática, utilizando a metodologia da Sala de Aula Invertida com os elementos de colaboração, desenvolvido por Honório (2016). A implementação foi realizada em uma turma do $9^{\circ}$ ano do ensino fundamental II do Colégio Ágora da cidade de Viçosa - MG nos meses de outubro e novembro de 2016.

Entende-se por "Processo", um método, sistema, maneira de agir ou conjunto de medidas tomadas para atingir algum objetivo, no caso específico da pesquisa, um método para implementar a metodologia Sala de Aula Invertida com o apoio dos elementos de colaboração.

\section{Sala de Aula Invertida e a Colaboração}

$\mathrm{O}$ uso da modalidade blended learning tem sido a tendência em muitos cursos de Educação a Distância (EAD) no Brasil [Velente, 2014]. No momento de estudo presencial, a participação do professor como mediador é indispensável, no qual ele deve valorizar as interações interpessoais e ser complementar às atividades online, proporcionando um processo de ensino e de aprendizagem mais eficiente, interessante e personalizado. [Staker; Horn, 2012 apud Valente, 2014, p. 84].

Segundo Valente (2014), a Flipped Classroom, conhecida no Brasil como Sala de Aula Invertida, é uma metodologia derivada do blended learning. Nas palavras de seus criadores Jonathan Bergmann e Aaron Sams, o conceito da metodologia é que, o 
que antes era feito na sala de aula do modelo tradicional, agora é executado em casa enquanto as atividades que eram realizadas sozinhas pelos alunos como tarefa de casa, agora é executada em sala de aula [Bergmann; Sams, 2016].

Os alunos estudam os conteúdos e as instruções online através de vídeos, aulas ou outros materiais disponibilizados pelo professor antes de ir para sala de aula, que agora passa a ser o local para trabalhar os conteúdos já estudados previamente, para realizar atividades práticas como resolução de problemas e projetos, para discutir em grupo, laboratórios e outros locais [Valente, 2014].

O tipo de material que o aluno utiliza nos estudos online varia de acordo com a proposta pedagógica do professor, que pode disponibilizar em um ambiente virtual uma videoaula, um tutorial ou até mesmo textos com um questionário.

A Sala de Aula Invertida não inverte apenas a estrutura do processo de aprendizagem, mas também transforma os papeis de alunos e dos professores. Diferente do modelo tradicional de ensino, a aula agora gira em torno dos alunos, em que os mesmos têm o compromisso de assistir os vídeos e fazer perguntas adequadas, recorrendo sempre ao professor para ajudá-lo na compreensão dos conceitos. O professor agora está presente para dar o feedback aos alunos de modo a esclarecer as dúvidas e corrigir os erros, pois agora sua função em sala de aula é ampará-los e não mais transmitir informações [Bergmann; Sams, 2016].

A inversão da sala de aula pode proporcionar aos alunos um ambiente propício à aprendizagem colaborativa. Bergmann e Sams (2016) contam que, como no novo modelo podem passar grande parte do tempo com os alunos conversando e respondendo perguntas, podem optar por trabalhar em pequenos subgrupos $\mathrm{e}$ orientar individualmente a aprendizagem de cada um. À medida que vão trabalhando em conjunto, os alunos ficam menos dependentes dos professores, pois tiram dúvidas uns com os outros.

O conceito de aprendizagem colaborativa está relacionado ao conceito de aprender e ensinar em grupo. Tem sido objeto de estudos de muitos teóricos, pesquisadores e educadores, desde o séc. XVIII e, principalmente, a partir da segunda metade do século XX com o grande avanço tecnológico da sociedade [Leite, at al., 2005].

Na visão de Jeong e Hmelo-Silver (2016) a aprendizagem colaborativa é muitas vezes definida como duas ou mais pessoas trabalhando em direção a um objetivo de aprendizagem compartilhada.

Com o surgimento da informática, através do uso do computador, tem-se o início de uma profunda transformação nos processos de comunicação da humanidade, fazendo assim com que muitos educadores buscassem uma integração entre os recursos oferecidos por estas máquinas e o processo de ensino e aprendizagem. A utilização das redes de computadores, principalmente a Internet, permitem a criação de espaços onde os indivíduos podem interagir e trabalhar colaborativamente, dando origem a uma área de estudos conhecida como Aprendizagem Colaborativa Apoiada por Computador (Computer Supported Collaborative Learning - CSCL).

Em relação ao aprendizado de matemática, um problema a ser tratado pelos projetos de ferramentas CSCL diz respeito aos instrumentos necessários à comunicação. $\mathrm{Na}$ construção de ambientes colaborativos de ensino da matemática, devem-se priorizar 
aspectos relacionados ao tipo de atividade desenvolvida e à representação utilizada, principalmente, às ferramentas matemáticas necessárias à colaboração [Mattos; Barbastefano; Moraes, [s.d.]].

O surgimento de uma nova sociedade conectada transformou a maneira de trabalhar em equipe, de tal forma que o paradigma de comando e controle, através do qual a comunicação se fazia de cima para baixo, já não é mais eficaz. Nesse novo contexto de sociedade, ela é substituída por um modelo menos hierarquizado e mais participativo, através do qual predominam a comunicação, a coordenação e a cooperação, intitulado modelo de colaboração 3C [Fuks et al., 2002].

De acordo com o modelo, a comunicação entre os indivíduos gera compromissos entre os mesmos, ficando para a coordenação a responsabilidade de gerenciar os conflitos e organizar as tarefas para prevenir perdas na comunicação e evitar esforços desnecessários no momento de cooperação. A cooperação, por sua vez, é o trabalho em conjunto da equipe em um espaço compartilhado, que objetivam e executam as tarefas organizadas pela coordenação [Rosa; Vieira, 2011].

\subsection{O "Processo" de Sala de Aula Invertida Colaborativa}

O Processo desenvolvido por Honório (2016) tem o objetivo de planejar, implementar e avaliar a metodologia da Sala de Aula Invertida, pautado em elementos de colaboração. A figura a seguir apresenta de forma sistematizada as três fases do processo.

FASE 1

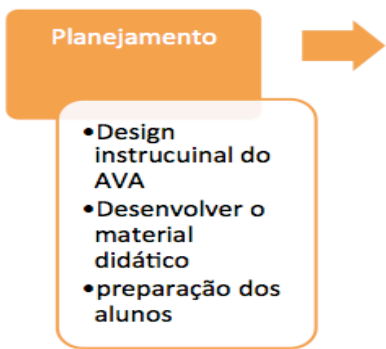

FASE 2

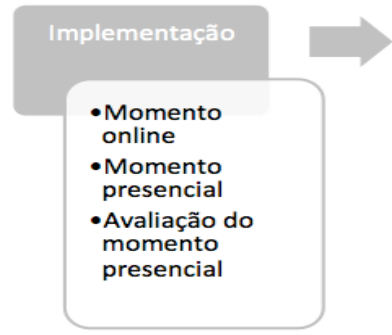

FASE 3

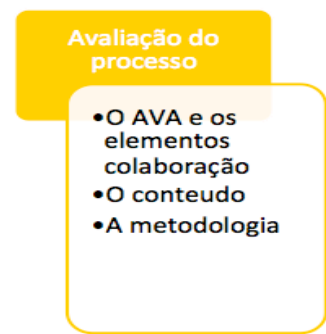

Figura 1: Fases do Processo de Sala de Aula Invertida Colaborativa

Fonte: Honório, 2016

A primeira fase tem como objetivo realizar a preparação de todos os elementos necessários para a implementação da metodologia, bem como dos atores envolvidos, nesse caso, os alunos. Para isso, é necessária a realização de três tarefas: o design instrucional do ambiente virtual, o desenvolvimento do material didático, que será disponibilizado online aos alunos (vídeos, listas de exercícios e etc) e, a preparação dos alunos para a implementação da metodologia.

A implementação da metodologia, que é a segunda fase do Processo, é composta de três momentos: momento online, momento presencial e momento de avaliação do encontro presencial. O primeiro momento, o "momento online" será aquele destinado aos estudos prévios dos alunos. Ele acontecerá no AVA e que devem estar presentes os elementos de colaboração do modelo 3C: a comunicação, a coordenação e a cooperação. O segundo momento da fase de implementação da metodologia é o momento presencial ou encontro presencial onde os professores podem interagir de 
forma ativa para esclarecer as dúvidas dos alunos quanto ao conteúdo da videoaula e, colocar em prática os conhecimentos adquiridos nos estudos prévios.

Após o momento presencial, deve ocorrer o momento de avaliação do encontro presencial. Esse momento acontece utilizando as ferramentas do AVA, em que o objetivo é avaliar o aprendizado do aluno de forma pontual, ou seja, avaliar a aprendizagem pertinente ao conteúdo abordado na videoaula e as discussões no momento presencial.

A terceira fase consiste em avaliar o Processo proposto. Segundo [Filatro, 2004], a avaliação envolve o acompanhamento, a revisão e a manutenção do processo proposto e, assim, a criação de critérios para verificar se ele foi efetivo nos resultados da aprendizagem. A avaliação deste Processo é realizada de três formas: mediante os relatórios do AVA, observação em sala de aula e questionários aplicados aos alunos.

\section{Procedimentos metodológicos}

A metodologia utilizada foi o estudo de caso, com observações das interações, reações e as construções de conhecimento pelos alunos de uma turma de 25 alunos do $9^{\circ}$ ano do Ensino Fundamental II de um colégio particular da cidade de Viçosa - MG. A implementação do Processo ocorreu na disciplina de matemática e teve início no dia 10 de outubro de 2016, quando se iniciou a primeira fase, e se encerrou no dia 10 de novembro do mesmo ano, com a sua terceira fase. Para a aplicação do Processo, foi utilizado o AVA denominado "Sala de Aula Virtual", disponibilizado pela escola.

\section{Apresentação e discussão dos resultados}

\subsection{Fase 1: O planejamento}

A primeira fase do Processo é dividida em três etapas: o design instrucional (DI) do ambiente virtual de aprendizagem, a preparação do material didático e a preparação dos alunos através de seminários.

O design instrucional do AVA, trata do planejamento do ambiente virtual, em que o professor seleciona as ferramentas colaborativas que deseja que seus alunos utilizem. No DI realizado para esse Processo, a seleção das ferramentas foi efetuada baseada no modelo de colaboração 3C. Foram selecionados o fórum de discussões e o email para a comunicação, a agenda virtual e o painel de avisos de desempenho para os serviços de coordenação e a ferramenta Wiki para a cooperação.

A segunda etapa da primeira fase do Processo tratou do planejamento do material didático, ou seja, planejamento e gravação das videoaulas.

O conteúdo matemático escolhido para a aplicação da metodologia foi Razões Trigonométricas no Triangulo Retângulo. A escolha se deu pelo fato de ser o conteúdo previsto para esse período no planejamento anual da turma. Para a conclusão do conteúdo, projetou-se um período de duas semanas, onde, os alunos tiveram um total de 5 aulas (momentos presenciais) com duração de 50 minutos cada.

A gravação e edição das videoaulas foram feitas pela equipe técnica do Centro de Educação a Distância (Cead) da UFJF. Seguindo as instruções dos autores Bergmann e Sams (2016), os vídeos possuem duração máxima de 10 minutos, e foram disponibilizados aos alunos no AVA. 
Nesta etapa, também foi determinada a forma da avaliação da aprendizagem, na qual utilizamos ferramentas de avaliação online do AVA na forma de testes discursivos e objetivos e, a ferramenta de "Fórum" para avaliar com uma determinada pontuação as interações dos membros de cada grupo.

A terceira etapa da primeira fase do Processo ocorreu com a preparação dos alunos, cujo objetivo foi fazer com que os estes compreendessem alguns conceitos relacionados à aprendizagem colaborativa e os elementos de colaboração, conhecessem a proposta da metodologia da Sala de Aula Invertida e também, para que se familiarizem com o Ambiente Virtual de Aprendizagem, conhecendo como utilizar suas ferramentas e suas funcionalidades. Esta, teve início com o primeiro seminário, cujo tema abordado foi Aprendizagem Colaborativa e os elementos de colaboração. $\mathrm{O}$ segundo seminário, teve como objetivo apresentar aos alunos a metodologia Sala de Aula Invertida. E, o terceiro e último seminário foi realizado na sala de informática da escola com um formato mais prático. O objetivo desse encontro foi ensinar os alunos a utilizarem o ambiente virtual da escola, principalmente o espaço denominado "sala de aula virtual".

\subsection{Fase 2: implementando o Processo}

A implementação da metodologia foi realizada ao longo de duas semanas, totalizando 5 aulas. As aulas foram destinadas para os momentos presenciais segundo o horário da escola, cujas aulas de matemática na turma do $9^{\circ}$ ano aconteceram na segunda-feira, quarta-feira e sexta-feira. A implementação da metodologia no decorrer da semana teve a seguinte sequência:

\begin{tabular}{|c||c||}
\hline \multicolumn{1}{|c|}{ Momento } & Dia da semana \\
\hline \hline Online & Antes da segunda-feira, terça-feira, quinta-feira e após a sexta-feira \\
\hline \hline Presencial & Segunda-feira, quarta-feira e sexta-feira \\
\hline \hline Avaliação do momento presencial & Disponível logo após o encontro presencial \\
\hline \hline
\end{tabular}

Tabela 1 - Planejamento dos momentos

Fonte: Honório, 2016

Para os momentos online foram criados avisos no "Painel de avisos" do AVA e enviado $e$-mail aos alunos, informando a disponibilidade das videoaulas para download. O objetivo principal foi que os alunos assistissem as videoaulas e no fórum discutissem sobre a teoria e a resolução dos exercícios que estavam disponibilizados no final de cada videoaula. Os alunos foram divididos em grupos de 4 a 5 integrantes, para cada grupo foi criado um fórum de discussão no AVA, totalizando 4 fóruns.

Após os momentos online, ocorreram os encontros presenciais com discussões sobre as dúvidas em relação aos conteúdos das videoaulas e, na sequência destes, a avaliação da aprendizagem com a disponibilização de testes no AVA, cujo conteúdo contemplado referia-se à videoaula anteriormente assistida e aos exercícios realizados em cada momento presencial.

\subsection{Fase 3: Avaliando o Processo}


A fase de avaliação do Processo foi planejada e realizada a partir das ideias de Filatro (2004), em que a autora sugere que a avaliação seja realizada a partir de três definições, o acompanhamento, a revisão e a manutenção.

Segundo a autora, para a definição do acompanhamento, as seguintes questões devem ser respondidas: Como o Processo será avaliado? Quem fará a avaliação? Quais os resultados finais da aprendizagem?

Em resposta à primeira questão, o Processo foi avaliado por observação em sala de aula, observação e análise dos dados produzidos no ambiente virtual de aprendizagem e pelo feedback dos alunos a partir da aplicação de um questionário.

Na sala de aula foi observado o diálogo entre os membros de cada grupo, a fim de verificar se nos encontros presenciais estes, refletiram de forma conjunta sobre o conteúdo das vídeoaulas, estimulando assim a construção do conhecimento.

Observou-se que nos encontros presenciais a interação entre os membros dos grupos os deixou mais independentes do professor, pois as dúvidas acerca do conteúdo das videoaulas de algum aluno na maioria das ocasiões foram sanadas por outro membro do grupo. Essa independência do auxílio do professor criada por partes dos alunos confirmam as hipóteses de Bergmann e Sams (2016) e de Munhoz (2015), que afirmam que na metodologia Sala de Aula Invertida, os alunos se tornam mais independentes e dão ao professor a oportunidade de dar mais atenção a estes, sanando dúvidas do conteúdo estudado na videoaula.

Também, a partir das observações das interações dos alunos nos momentos presenciais, percebeu-se que eles utilizaram esse momento para compartilhar com outros alunos as suas maneiras próprias de compreender o conteúdo.

No ambiente virtual de aprendizagem foi observado se houve colaboração entre os alunos. Essa observação foi realizada baseada no modelo de colaboração 3C [FUKS et al., 2002], verificando se os grupos utilizaram e se apropriaram dos elementos de colaboração nos momentos online. A partir da observação e análise dos dados registrados no AVA, foi possível constatar que a comunicação entre os alunos ocorreu de forma satisfatória no fórum de discussões, de modo que os alunos utilizaram bem o espaço para interagir e contribuir para a construção do conhecimento dos outros integrantes do seu grupo.

No que diz respeito à cooperação, percebeu-se que nem todos os alunos se apropriaram desse elemento, pois alguns alunos não utilizaram as ferramentas destinadas à cooperação. No fórum de discussões, alguns alunos cooperaram a partir de postagens de resolução de exercícios cujos outros membros do grupo tiveram dúvidas e, no resumo teórico, poucos alunos fizeram a edição adicionando informações que poderiam ser consultadas pelos outros estudantes.

Para obter o feedback dos alunos quanto ao Processo, foi aplicado um questionário cujas perguntas foram elaboradas a partir de quatro aspectos: quanto a utilização de tecnologias nas aulas de matemática, quanto a metodologia Sala de Aula Invertida, quanto a aprendizagem colaborativa $\mathrm{e}$ ainda, sobre $\mathrm{o}$ processo de aprendizagem. 
VI Congresso Brasileiro de Informática na Educação (CBIE 2017)

Anais do XXIII Workshop de Informática na Escola (WIE 2017)

Em relação ao aspecto "utilização de tecnologias nas aulas de matemática, os alunos apontaram quase na sua totalidade que estes recurso deixam os alunos mais motivados a participar das atividades.

Quanto ao aspecto "Sala de Aula Invertida", todos os alunos responderam de forma positiva e aprovaram a utilização da metodologia nas aulas de matemática.

Referentes ao aspecto "aprendizagem colaborativa e os elementos de colaboração", com as respostas dos alunos, pode-se constatar a eficiência dos serviços de coordenação/professor, pois uma grande maioria dos alunos compreenderam que as diversas notificações os motivaram a realizar as atividades disponíveis no ambiente virtual de aprendizagem.

O último aspecto abordado no questionário, foi processo de aprendizagem e, as respostas dos alunos apontam que $96 \%$ deste, concluíram que o "Processo" implementado tornou a aprendizagem mais efetiva.

Em resposta à segunda questão apresentada por Filatro (2004): "quem fará a avaliação?" e conforme dados apresentados acima, somente os alunos participaram da avaliação do "Processo".

Já a terceira e última questão, "quais foram os resultados finais da aprendizagem?", refere-se ao desempenho dos alunos quanto ao conteúdo estudado, o índice de aprovações, reprovações, desistência e etc [Filatro, 2004]. Neste Processo, essa questão foi respondida a partir da observação do rendimento dos alunos.

Para a avaliação da aprendizagem no processo, houve a distribuição de 6 pontos: 3,5 pontos para os testes online, 1,5 pontos para a participação das atividades no momento online e 1 ponto, para as atividades realizadas no momento presencial. Os 6 pontos distribuídos substituiram o $2^{\circ}$ teste de mesmo valor marcado pela coordenação pedagógica, que deveria ser aplicado de acordo com o calendário escolar durante aquele período. Na divisão da pontuação entre as atividades, optou-se por destinar uma pontuação maior para as atividades online, justamente para motivar os alunos a interagirem e realizar as atividades no AVA.

A pontuação de cada aluno ficou registrada no ambiente virtual pelo serviço de coordenação nas ferramentas de gerenciamento. A turma alcançou uma média de 5,6 pontos no somatório das avaliações, de modo que ao se observar as médias individuais, apenas 3 alunos ficaram abaixo de $60 \%$ do total das notas distribuídas. Os 6 pontos distribuídos durante a implementação da metodologia é a pontuação referente ao segundo teste do cronograma escolar e, ao fazer uma comparação entre o rendimento da turma no primeiro teste (sala de aula normal) e o rendimento da turma na implementação da metodologia, percebe-se uma melhoria na média geral dos alunos, pois no primeiro teste a turma obteve uma média geral igual a 4,1 pontos e 9 alunos ficaram abaixo dos $60 \%$ do valor total do teste.

A melhoria do desempenho dos alunos quando comparado ao desempenho obtido no primeiro teste reforça as ideias defendidas por Munhoz (2015), pois o autor afirma que na metodologia Sala de Aula Invertida os resultados da aprendizagem são superiores aos do método tradicional de ensino. 
A revisão, que é uma das definições apresentadas por Filatro (2004) e visa descrever quais problemas foram detectados, quais erros podem ser corrigidos e assim, como o Processo pode ser aperfeiçoado.

Durante a $1^{\circ}$ fase do Processo, a preparação, foram identificados dois problemas. O tempo dedicado aos seminários na preparação dos alunos não foi o suficiente para introduzir conceitos novos aos alunos, ou mesmo treiná-los e habituá-los a acessarem a plataforma digital e utilizarem algumas ferramentas do AVA que antes eles não tinham contato, como o e-mail, por exemplo.

Outro problema nessa fase foi na preparação do material didático, mais especificamente, na produção das videoaulas. Os vídeos foram gravados para serem disponibilizados para download no AVA, o que prejudicou os alunos que tinham uma internet com baixa velocidade.

$\mathrm{Na}$ fase da implementação da metodologia, que corresponde a $2^{\circ}$ fase do Processo, foi identificado um problema na apropriação do elemento cooperação do modelo 3C. Alguns alunos não utilizaram as ferramentas destinadas aos serviços de cooperação, o que pode ter prejudicado em certo nível a sua colaboração no processo de aprendizado dos membros do seu grupo.

$\mathrm{Na} 3^{\circ}$ fase do Processo, a avaliação, foram identificados elementos que podem ser aprimorados para se obter resultados mais detalhados. O questionário criado com a finalidade de obter o feedback dos alunos apresentava apenas duas alternativas para serem escolhidas, onde os alunos escolhem sim ou não, não dando a eles a opção de dar uma resposta intermediária.

Finalizando a fase de avaliação temos a manutenção, definição essa que analisa e discute as ações que podem possibilitar a continuidade do projeto como uma nova edição. Uma ação para a continuidade seria a correção dos problemas detectados na "revisão" e, como possíveis soluções aos problemas detectados, propomos as seguintes ações:

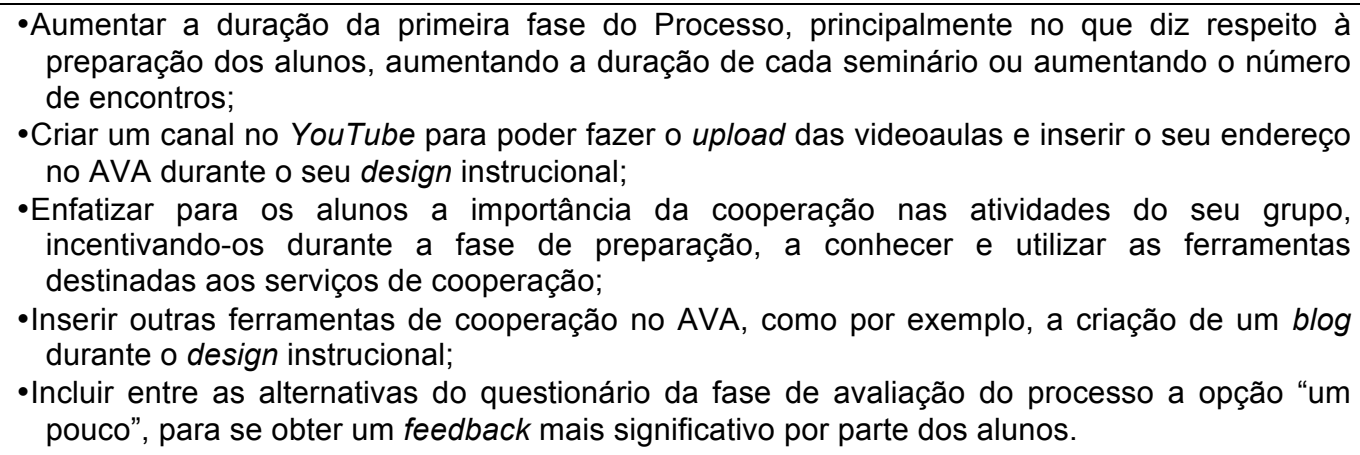

\section{Considerações Finais}

A partir dos resultados obtidos na experiência da implementação do "Processo" de Sala de Aula Invertida no ensino da Matemática, pode-se concluir que a apropriação dos elementos de colaboração pelos alunos tornou-os mais independentes do professor tanto nos momentos online quanto nos momentos presenciais. A comunicação entre eles no AVA, a coordenação das atividades online e a cooperação por parte dos integrantes dos 
VI Congresso Brasileiro de Informática na Educação (CBIE 2017)

Anais do XXIII Workshop de Informática na Escola (WIE 2017)

grupos, implicaram em uma aprendizagem mais autônoma, de modo que ao longo a implementação da metodologia, os alunos interagiam para discutir sobre suas dúvidas e compreensões dos conteúdos matemáticos abordados nas videoaulas.

Quanto a metodologia Sala de Aula Invertida, pudemos concluir, a partir das observações em sala de aula e da avaliação do Processo, que a metodologia teve uma boa aceitação por parte dos alunos, visto que os mesmos sugeriram que o método fosse utilizado até o encerramento do ano letivo.

Desta forma, pode-se concluir que um "Processo" que dê suporte a colaboração na Sala de Aula Invertida pode potencializar a metodologia, permitindo que os alunos criem espaços para refletirem sobre os conteúdos matemáticos estudados, a partir de uma aprendizagem mais autônoma, além de motivá-los aos estudos prévios de modo a enriquecer os encontros presenciais.

\section{Referências}

Bergmann, J. and Sams, A. (2016) "Sala de aula invertida - uma metodologia ativa de aprendizagem". 1. ed., Rio de Janeiro.

Borba, M. C. (2010) "Softwares e Internet na Sala de Aula de Matemática". Anais do X Encontro Nacional de Educação Matemática, 1-11.

Ellis, C.A.; Gibbs, S.J. and Rein, G.L. (1991) "Groupware - Some Issues and Experiences". Communications of the ACM 34, 38-58.

Filatro, A. (2004) "Planejamento, design, implementação e avaliação de programas de educação on-line”. XI Congresso Internacional de Educação a Distância.

Fuks, H.; Raposo A. B.; Gerosa M. A. and Lucena C. J. P. (2002) "O modelo de colaboração 3C e a engenharia de goupware". [s.1.] Pontifícia Universidade Católica do Rio de Janeiro.

Honório, H. L. G.(2016) "Sala de Aula Invertida: uma abordagem colaborativa na aprendizagem de matemática". PPGEM/UFJF. Juiz de Fora.

Jeong, H.; and Hmelo-Silver, C. E. (2016) "Seven affordances of computer-supported collaborative learning: How to support collaborative learning? How can technologies help?" Educational Psychologist. v. 51, n. December, 247-265.

Leite, C.; Passos M. O. A.; Torres P. L. and Alcântara P. R. A. (2015) "Aprendizagem colaborativa na educação a distancia on-line". [s.l: s.n.]. ABED.

Mattos, F.; Barbastefano, R. and Moraes, T. (2001) "Funcionalidades e Características para Compor". [s.d.].

Munhoz, A. S. (2015) "Vamos inverter a sala de aula?" .1. ed. Clube de Autores.

Rosa, R. and Vieira, M. (2011) "Coordenação nas Atividades Colaborativas em Ambientes de Aprendizagem - Uma Avaliação na Implementação de Arquiteturas Pedagógicas”. RENOTE - Revista Novas Tecnologias na Educação, v.9, n.1.

Valente, J. A. (2014) "Blended learning e as mudanças no ensino superior: a proposta da sala de aula invertida”. Educar em Revista, v. Edição Esp, n. 4, 79-97. 